\title{
Outbreak of armyworms in eastern Bay of Plenty
}

\author{
P.J. Gerard ${ }^{1}$, P.J. Addison ${ }^{2}$, P. Hedley ${ }^{3}$, N.L. Bell ${ }^{1}$ and C.J. Vink ${ }^{4}$ \\ ${ }^{1}$ AgResearch, Ruakura Research Centre, Private Bag 3123, Hamilton, New Zealand \\ ${ }^{2}$ Nufarm, PO Box 22407, Auckland 1640, New Zealand \\ ${ }^{3}$ DairyNZ, PO Box 861, Whakatane 3158, New Zealand \\ ${ }^{4}$ AgResearch, Lincoln, Private Bag 4749, Christchurch, New Zealand \\ Corresponding author: pip.gerard@agresearch.co.nz
}

Tropical armyworm (Spodoptera litura) caused widespread serious damage to Bay of Plenty lucerne crops and clover, plantain and chicory in pastures in April and early May 2011, reaching populations at high as $100 / \mathrm{m}^{2}$. This outbreak was preceded by an outbreak of cosmopolitan armyworm (Mythimna separata) attacking maize and grasses. Tropical armyworm is a minor pest of subtropical crops, such as kumara, in Northland. The last widespread outbreak was in autumn 1975 and resulted in serious pasture and crop damage in Northland and Auckland and minor damage in Bay of Plenty, Taranaki and Manawatu. The current outbreak in Bay of Plenty may be climate related with a mild and extremely wet winter in 2010, above average spring and summer temperatures and near record summer rainfall. These conditions may have allowed tropical armyworm to complete four generations to build up to outbreak levels. In addition, dry spring soil conditions during maize establishment meant poor weed control, a known factor to predispose problems with cosmopolitan armyworm, which has a similar life cycle to tropical armyworm. Similar weather patterns are expected to increase in frequency with climate change.

\section{Philobota sp. (Lepidoptera: Oecophoridae), a potential new pasture pest in New Zealand}

\author{
A.J. Popay ${ }^{1}$ and D. Gunawardana ${ }^{2}$ \\ ${ }^{1}$ AgResearch, Ruakura Research Centre, Private Bag 3123, Hamilton, New Zealand \\ ${ }^{2}$ Plant Health and Environment Laboratory, Ministry of Agriculture and Forestry, PO Box 2095, \\ Auckland 1050, New Zealand \\ Corresponding author: alison.popay@agresearch.co.nz
}

In February 2010, caterpillars initially identified as a species of Philobota (Lepidoptera: Oecophoridae) were found in a nursery area at Ruakura Research Centre in Hamilton. The identification was confirmed by MAF's Plant Health and Environment Laboratory (PHEL). This genus is endemic to Australia where over 400 species are known, a few of which are regarded as minor pests of pasture. A survey of the Ruakura site found Philobota in three other areas, two of which bordered urban areas. It was found infesting perennial ryegrass and tall fescue trials in two parts of the campus and in pasture areas in the other two locations, suggesting this insect is primarily a grass feeder. It is highly likely Philobota is not confined to Ruakura and there is no evidence that the infestation originated at this site. Although few live caterpillars could be found by August 2010, observations in 2011 suggest populations have multiplied in at least one trial site. Commonly called the pasture tunnel moth, this insect is univoltine and weaves characteristic tunnels from grass and debris with 'chimneys' that protrude above ground. Caterpillars reared at PHEL yielded only female moths, which have been tentatively identified as Philobota nr. pilipes. 